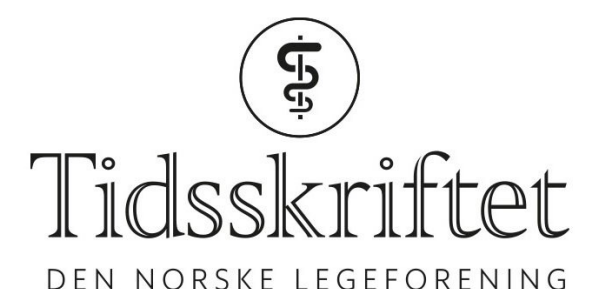

DEN NORSKE LEGEFORENING

\title{
Seinblødning etter tonsilleoperasjon
}

ORIGINALARTIKKEL

SVERRE MORTEN ZAHL

E-post: sverre.morten.zahl@helse-mr.no

Øyre-nase-halsavdelinga

Klinikk Ålesund sjukehus

Helse Møre og Romsdal

Sverre Morten Zahl er spesialist i øre-nese-halssykdommer og overlege.

Forfatteren har fylt ut ICMJE-skjemaet og oppgir ingen interessekonflikter.

\section{BAKGRUNN}

Tonsillektomi og tonsillotomi er vanlige kirurgiske prosedyrer, spesielt blant barn og unge. Postoperativ seinblødning er en komplikasjon som kan være dramatisk og farlig. Vi ville kartlegge forekomsten av seinblødninger og assosierte risikofaktorer ved Ålesund sjukehus.

\section{MATERIALE OG METODE}

Undersøkelsen er basert på en retrospektiv journalgjennomgang av alle pasienter som fikk utført tonsilleoperasjon ved Ålesund sjukehus i femårsperioden 2015-2019.

\section{RESULTATER}

Av 1394 pasienter som gjennomgikk tonsilleoperasjon ble tonsillektomi utført hos 1 285 pasienter og tonsillotomi hos 109 pasienter. 30 pasienter $(2,2 \%)$ fikk tidlig postoperativ blødning ( $<24$ timer). 20 pasienter $(1,4 \%)$ ble innlagt grunnet seinblødning ( $>24$ timer), etter gjennomsnittlig 5,4 dager. Fem pasienter $(0,4 \%)$ ble reoperert på grunn av seinblødning. Ingen seinblødning ble registrert etter tonsillotomi. $\varnothing \mathrm{kt}$ risiko for seinblødning ble funnet for pasienter 16 år eller eldre og pasienter med tidlig postoperativ blødning.

\section{FORTOLKNING}

Andelen seinblødninger var lav sammenliknet med internasjonale studier. Våre tall er trolig representative for flere øre-nese-hals-avdelinger i Norge og kan være nyttig informasjon til behandlere og pasienter før tonsilleoperasjon.

Fjerning av mandlene (tonsillektomi) er et vanlig kirurgisk inngrep. I 2017 ble det utført 9 600 slike operasjoner i Norge (1). Indikasjonene for operasjon er som regel enten store mandler som gir symptomer som svelgvansker, snorking og pustestopp, hyppige, antibiotikakrevende halsbetennelser eller kronisk tonsillitt. Ofte vil bakgrunnen være en kombinasjon av disse kriteriene. Mandler opereres i alle aldre, men barn, ungdom og unge 
voksne utgjør størsteparten av pasientgruppen. Hos små barn gjøres gjerne også adenotomi (fjerning av adenoide vegetasjoner, "falske mandler») som en del av inngrepet. I tilfeller der problemet er store mandler, men lite infeksjoner, kan det gjøres tonsillotomi, hvor kun deler av mandlene fjernes.

Tonsilleoperasjon regnes som et trygt inngrep, men noen komplikasjoner forekommer, for eksempel respirasjonsvansker ved narkose, infeksjon, smerter, dehydrering og blødning (2, 3). De postoperative blødningene deles gjerne inn i tidlige (første 24 timer) og seine $(>24$ timer) (4). Seinblødning er en sjelden, men fryktet komplikasjon, som i praksis skjer etter at pasienten er utskrevet fra sykehus. Dødsfall har forekommet (5). Hyppigheten av seinblødning oppgis til 2-4\% (3, 6, 7). Blødningsrisikoen påvirkes blant annet av alder, kjønn, indikasjon, type inngrep (tonsillektomi eller tonsillotomi) og kirurgisk teknikk (8, 9).

I denne studien har vi gjennomgått tonsilleoperasjoner gjennom en femårsperiode ved en norsk øre-nese-hals-avdeling og kartlagt tidlige og seine blødninger samt eventuelle assosierte faktorer.

\section{Materiale og metode}

Samtlige tonsilleoperasjoner ved avdelingen utført fra 1. januar 2015 til 31. desember 2019 ble identifisert gjennom pasientadministrativt system. Følgende koder fra klinisk prosedyrekodeverk (NCSP) ble benyttet i pasientsøket: EMB1o (tonsillektomi), EMB12 (reseksjon av tonsill), EMB15 (intrakapsulær tonsilledestruksjon) og EMB2O (adenotonsillektomi). Det ble også gjort søk etter pasienter innlagt med postoperativ blødning i samme tidsperiode (ICD-10-kode T81.o (blødning og hematom som komplikasjon til kirurgiske og medisinske prosedyrer)). Pasienter innlagt med blødning etter tonsilleoperasjon i vår avdeling ble inkludert. Pasienter som ble operert ved andre klinikker eller hadde postoperative blødninger etter andre inngrep, ble ekskludert.

Pasientrelatert informasjon som alder, kjønn, andre sykdommer og operasjonsindikasjon ble registrert. I tillegg ble det hentet ut informasjon om inngrepet, som operat $ø r$, kirurgisk teknikk, hemostasetiltak og eventuelle per- og postoperative komplikasjoner. Tidlig blødning ble definert som blødning i tidsrommet etter ekstubasjon og fram til 24 timer etter operasjon. Blødning fra 24 timer postoperativt og inntil fire uker ble betegnet som seinblødning.

Øyre-nase-halsavdelinga ved Ålesund sjukehus betjener primært en befolkning på 145000 innbyggere. Ved avdelingen utføres tonsilleoperasjoner på barn og voksne.

Tonsilleoperasjoner hos voksne blir også utført ved en privat klinikk i Ålesund. Pasienter med økt risiko for komplikasjoner, som blødningstilstander, lav vekt $(<10 \mathrm{~kg})$ eller kraniofaciale misdannelser, henvises gjerne til universitetsklinikk for operasjon.

Mange pasienter kan behandles dagkirurgisk, men ved relevant komorbiditet, alder under fire år eller ved lang reisevei $(>1$ times kjøring og/eller en fergereise) utskrives pasienten påfølgende dag.

Ved operasjon av små barn, gjerne under tre år, eller ved forventet komplisert inngrep, utføres operasjonen av spesialist. Utover dette fordeles operatøroppgaven tilfeldig mellom leger i spesialisering (LIS) og overleger. Erfaringsmessig utfører LIS-leger 10-20 inngrep sammen med overlege før vedkommende får være selvstendig operatør.

Inngrepene ble utført i intubasjonsnarkose, og hos samtlige pasienter ble det satt infiltrasjonsanestesi peritonsillært i form av lidokain-adrenalin $10 \mathrm{mg} / \mathrm{ml}+5 \mu \mathrm{g} / \mathrm{ml}$. Ved tonsillektomi incideres skarpt i fremre ganebue, deretter fridissekeres tonsillene kapselnært, som regel med disseksjonssug (kald teknikk). Ved tonsillotomi kan mediale del av tonsillene overskjæres eller klippes kaldt, eller det benyttes overskjæring med monopolar diatermi (varm teknikk). For hemostase benyttes alltid kompresjon med tupfer. Noen operatører benyttet hovedsakelig ligatur for ytterligere hemostase, mens andre benyttet bipolar diatermipinsett. 
For statistiske beregninger ble det benyttet Fishers eksakte test og khikvadrattest. Statistisk signifikans ble angitt som $\mathrm{p}$-verdi $<0,05$.

Studien er godkjent av Regional komité for medisinsk og helsefaglig forskningsetikk (REK) og helseforetakets personvernombud.

\section{Resultater}

Totalt 1394 pasienter gjennomgikk tonsilleoperasjon ved avdelingen i femårsperioden 2015-19, i gjennomsnitt 279 per år. Som vist i figur 1 var det en svak vekst i antall tonsillotomier i perioden, mens det totale antallet operasjoner sank. Hovedindikasjonen var store mandler hos 708 pasienter (51\%) og infeksjon hos 662 (47\%).

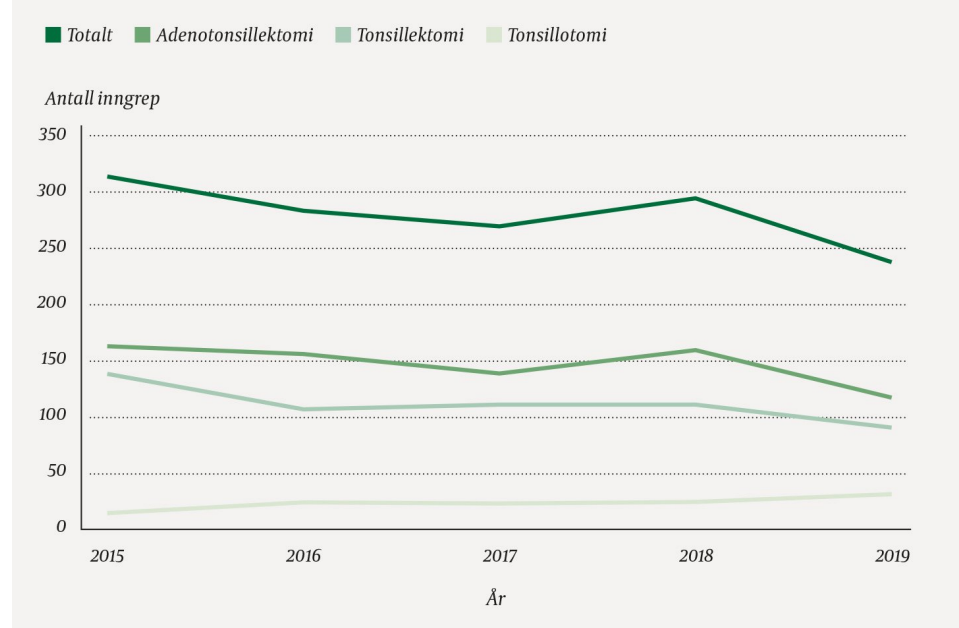

Figur 1 Årlig antall og type tonsilleoperasjoner ved Øyre-nase-halsavdelinga, Ålesund sjukehus $i$ perioden 2015-19 $(N=1394)$.

Adenotonsillektomi ble utført hos 731 pasienter (52\%), tonsillektomi hos 554 pasienter (40 \%) og tonsillotomi hos 109 pasienter (8\%). LIS-leger utførte 656 (47\%) av operasjonene, overleger utførte $653(47 \%)$ av operasjonene, mens 85 (6\%) ble utført av LIS-lege og overlege sammen. 1330 (95\%) av inngrepene ble utført med kald kirurgisk teknikk, mens 64 (5\%, kun tonsillotomier) ble utført med varm teknikk. Det totale antallet operatører i perioden var 16. For øvrige detaljer se tabell 1.

\section{Tabell 1}

Tonsilleoperasjoner ved Øyre-nase-halsavdelinga, Ålesund sjukehus i perioden 2015-19.

\begin{tabular}{|c|c|}
\hline & $n(\%)$ \\
\hline \multicolumn{2}{|l|}{ Antall opererte } \\
\hline Totalt & 1394 \\
\hline Gjennomsnitt per år & 279 \\
\hline \multicolumn{2}{|l|}{ Alder } \\
\hline Gjennomsnitt / median & $12 \mathrm{år} / 6,5 \mathrm{år}$ \\
\hline Spredning & 1,5-81 år \\
\hline Antall barn $\leq 15$ år & $966(69)$ \\
\hline Antall voksne $>15$ år & $428(31)$ \\
\hline \multicolumn{2}{|l|}{ Kjønn } \\
\hline Gutt/mann & $681(49)$ \\
\hline Jente/kvinne & $713(51)$ \\
\hline \multicolumn{2}{|l|}{ Hemostasetiltak } \\
\hline Kun kompresjon & $180(13)$ \\
\hline Ligatur & $637(46)$ \\
\hline Bipolar diatermi & $577(41)$ \\
\hline
\end{tabular}




\begin{tabular}{|cc|}
\hline & $\boldsymbol{n}(\%)$ \\
\hline Postoperativ håndtering \\
\hline Dagkirurgi & $542(39)$ \\
\hline Innleggelse & $852(61)$ \\
\hline Tidlig postoperativ blødning (<24 timer) & $30(2,2)$ \\
\hline
\end{tabular}

30 pasienter $(2,2 \%)$ hadde en tidlig blødning ( $<24$ timer). Tre av disse var utskrevet og ble reinnlagt. Av pasientene med tidlig blødning hadde 11 pasienter $(0,8 \%)$ blødning som krevde reoperasjon i narkose for å oppnå hemostase. Tre pasienter kunne behandles i våken tilstand med kompresjon mot blødningsfokus i svelget og bruk av bipolar diatermi. De vanligste tiltakene ved tidlig blødning var behandling med systemisk traneksamsyre samt observasjon på sengepost.

Totalt 20 pasienter $(1,4 \%)$ ble innlagt grunnet seinblødning. Fem (o,4\%) av disse ble operert. Det var ingen seinblødninger hos de 109 tonsillotomerte, mens andelen blant de (adeno)tonsillektomerte var 1,6\%. Tre pasienter med seinblødning hadde også hatt tidlig postoperativ blødning. Pasienter med tidlig blødning hadde signifikant $\varnothing \mathrm{kt}$ risiko for seinblødning $(p=0,01)$, relativ risiko 8,02 $(p<0,01)$. Seinblødningene oppsto i gjennomsnitt 5,4 dager (spredning 3-10 dager) etter primæroperasjonen.

Gjennomsnittlig alder for pasienter med tidlige blødninger var 18 år og for seinblødninger 17 år. Andelen voksne (16 år eller eldre) var signifikant høyere enn andelen barn både for tidlig blødning (16/428 mot 14/966, $p<0,01)$ og seinblødning (13/428 mot 7/966, $p<0,01)$. Det var ingen signifikant forskjell mellom kjønnene, verken ved tidlig blødning (17/681 mot 13/713, $p=0,39$ ) eller seinblødning (11/681 mot 9/713, $p=0,58)$, heller ikke når man justerte for alder. Det ble ikke funnet forskjell i blødningsrate mellom LIS-lege og overlege som operatør, verken ved tidlig blødning (16/656 mot 11/653, $p=0,34)$ eller seinblødning $(10 / 656$ mot 9/653, $p=0,83$ ). Ingen operatører hadde høyere blødningshyppighet enn 5,0 \% for tidlig blødning og $2,5 \%$ for seinblødning.

Det var ikke ulik blødningstendens for operasjoner med og uten bruk av bipolar diatermi som hemostase, verken ved tidlig blødning (15/577 mot 15/817, $p=0,33$ ) eller seinblødning (10/577 mot 10/817, $p=0,43)$. Bruk av bipolar diatermi ble også analysert med tanke på andelen som ble reoperert grunnet blødning, men det ble ikke funnet signifikant forskjell verken ved tidlig blødning (5/577 mot 6/817, $p=0,77)$ eller seinblødning $(4 / 577 \operatorname{mot} 1 / 817, p=$ $0,17)$.

\section{Diskusjon}

Hyppigheten av seinblødning etter tonsilleoperasjon var 1,4\% i studieperioden, og totalt $0,4 \%$ av de opererte pasientene hadde seinblødning som krevde reoperasjon i narkose. I en metaanalyse har man funnet seinblødning hos 2,6\% av adenotonsillektomerte barn (3). Hos voksne rapporteres vanligvis tall fra 2-6\% (9-11), men langt høyere tall er også publisert, selv i store studier $(8,12)$. I vårt materiale har vi skilt mellom tidlige og seine blødninger. Dette er vanlig i internasjonale studier og benevnes da som primær og sekundær blødning (4, 9, 10, 13, 14), ettersom man antar at dette er blødninger av ulik årsak/entitet. Tidlig blødning ses på som utilstrekkelig hemostase, mens seinblødning antas å skyldes en midlertidig sårbarhet i vevet under tilheling, som kan gi blødning ved for eksempel tidlig skorpeløsning eller lette traumer (15).

I 2017 ble det opprettet et nasjonalt kvalitetsregister i Norge (Tonsilleregisteret) som samler inn informasjon om tonsilleoperasjoner via tre spørreskjemaer (16). Det første fylles ut av operatøren i forbindelse med inngrepet, de to neste fylles ut av pasient/pårørende henholdsvis 30 dager og 6 måneder etter operasjonen. Registerets dekningsgrad (inklusjon ved operatør) har vært økende, til 65\% i 2019 (16). Dekningsgraden ved Øyre-nasehalsavdelinga i Ålesund var 84 \% i 2019. Ifølge registeret ble 7,8 \% reinnlagt grunnet blødning i Norge i 2019, tallet for Ålesund var 1\%. I 2019 ble det gjennomført 237 tonsilleoperasjoner ved Ålesund sjukehus. 195 av disse ble inkludert i Tonsilleregisteret ved operasjon. 
Imidlertid er det kun 97 pasienter som har besvart spørreskjemaene og som er inkludert i registerets beregning av blødningshyppighet. At Tonsilleregisteret er avhengig av aktiv tilbakemelding fra pasient/pårørende, er en viktig begrensning og gir risiko for responsskjevhet. Dette bekrefter behovet for journalgjennomgang som supplement til registeret.

I det følgende gjennomgås en del faktorer som kan påvirke blødningsrisikoen.

\section{ALDER}

Vi fant en $\varnothing \mathrm{kt}$ risiko for seinblødning hos pasienter over 15 år. Denne høyere risikoen hos voksne er velkjent fra tidligere studier $(9,11,17)$.

\section{KJØNN}

Vi fant ingen signifikant forskjell mellom kjønnene, verken blant barn eller voksne. I større studier er det sett en høyere risiko for seinblødning hos gutter og menn $(8,9,18)$. Årsaken til denne kjønnsforskjellen er ikke kjent.

\section{KIRURGISK TEKNIKK}

Ved vår avdeling brukes utelukkende kald teknikk ved tonsillektomi, og dette er det mest vanlige ved norske sykehusavdelinger (16). I noen observasjonsstudier har man konkludert med at kald teknikk kan gi lavere risiko for seinblødning $(9,10,18)$, men godt kunnskapsgrunnlag for dette foreligger ikke $(13,14)$. De mest brukte metodene for varm teknikk i Norge er bipolar- og monopolar diatermi (16). Fordelene ved varm teknikk skal være blant annet mindre peroperativ blødning og færre tidlige postoperative blødninger samt kortere operasjonstid (19).

\section{HEMOSTASE}

Ved vår avdeling benyttes alltid lokalanestesi med adrenalin ved tonsilleoperasjon grunnet antatt mindre peroperativ blødning og bedre postoperativ analgesi. En del avdelinger praktiserer ikke dette, trolig i frykt for å oppnå en «falsk» hemostase. Det er ikke funnet sammenheng mellom bruk av lokalanestesi med adrenalin og $ø$ kt postoperativ blødning i tidligere studier (20-22). Tiltak for hemostase etter fjerning av tonsillene kan omfatte kompresjon, ligatur/sutur, bipolar diatermi eller en kombinasjon av disse.

I rapporter basert på data fra det svenske tonsilleregisteret og det britiske helsevesenet har man konkludert med at det trolig foreligger en liten $\emptyset \mathrm{kt}$ risiko for seinblødning ved bruk av bipolar diatermi for hemostase sammenliknet med kald teknikk (kompresjon med eller uten ligatur/sutur) $(6,12)$. Vi fant ikke en slik sammenheng i vårt materiale. Man antar at termisk skade av omkringliggende vev kan være årsaken til den økte risikoen for seinblødning (23), og søkelys på forsiktig og spredt bruk av diatermi er muligvis en forklaring på forskjellene.

\section{OPERAT ØR}

Operatørens erfaring hadde ikke betydning for andelen seinblødning i vårt materiale. Større studier har visst det samme $(9,11)$. Andre studier igjen har vist at erfarne operatører har lavere andel seinblødninger (24-26). Vår erfaring er at tonsilleoperasjon er et relativt enkelt inngrep rent teknisk og at man tidlig kan utføre det selvstendig og få mengdetrening.

\section{TYPE INNGREP}

Tonsillotomi (reduksjon av mandlenes størrelse) er de senere årene blitt mer vanlig ved søvnapné hos barn, og det er god evidens for at dette er et bedre inngrep enn tonsillektomi hva angår postoperative smerter og risiko for seinblødning $(27,28)$. Foreløpig er bare et fåtall av våre pasienter behandlet med tonsillotomi, men trolig bør flere barn med tonsillehypertrofi vurderes for dette inngrepet, slik tendensen er i for eksempel Sverige 
(28). Et viktig motargument mot tonsillotomi er at det er en større tendens til gjenvekst av tonsiller (27) og dermed risiko for ny tonsilleoperasjon grunnet tonsillehypertrofi (29).

\section{TIDLIG POSTOPERATIV BLØDNING}

Hyppigheten av tidlig blødning var 2,2 \%. Dette er sammenliknbart med tilsvarende studier $(3,17,18)$. Tre pasienter med tidlig blødning hadde også seinblødning. Risikoen for seinblødning for pasienter med tidlig blødning er beskrevet tidligere (20), men må tolkes med forsiktighet i vår studie grunnet det lave antallet.

\section{BEGRENSNINGER OG SVAKHETER}

Studiens retrospektive design og manglende randomisering åpner for seleksjonsskjevhet, og resultatene må tolkes med forsiktighet. Blødningstallene i vårt materiale er lave i forhold til liknende studier. Det gjelder også dersom man sammenlikner med andre norske ørenese-hals-avdelinger (16). Til forskjell fra pasienter operert ved universitetsklinikker, har våre pasienter mindre komorbiditet og trolig mindre risiko for blødning, og en lavere andel komplikasjoner er derfor forventet. Hvorfor andre øre-nese-hals-avdelinger med lik størrelse og antatt lik pasientfordeling har til dels mye høyere andel postoperative blødninger i Tonsilleregisteret, gir ikke denne studien svar på. Imidlertid må den tidligere nevnte usikkerheten i registeret has in mente ved slike sammenlikninger. Tilsvarende studier som denne ved andre avdelinger vil være nyttig for å avdekke relevante ulikheter i behandlingen.

I denne studien regnet vi en blødning som relevant dersom pasienten ble innlagt. Vurderingen av om en pasient bør innlegges, kan trolig variere noe mellom ulike leger og ulike klinikker. I tillegg vil nok de fleste ha lavere terskel for å innlegge barn. Ytterligere en faktor er pasient/pårørende, men vårt inntrykk er at terskelen er lav for å ta kontakt ved blødning. Andelen pasienter som trengte reoperasjon er slik sett et «hardere» endepunkt. Vår erfaring er at pasientene reiser lite i ukene etter tonsilleoperasjon, men i teorien kan noen av pasientene ha blitt behandlet for seinblødning ved et sykehus utenfor helseforetaket og dermed ikke blitt registrert i denne studien.

\section{KONKLUSJON}

Andelen pasienter med tidlig- og seinblødning etter tonsilleoperasjon var henholdsvis 2,2 \% og 1,4\%. Til sammen $0,4 \%$ måtte reopereres grunnet seinblødning. Vi fant $\varnothing \mathrm{kt}$ risiko for seinblødning hos pasienter over 15 år og hos pasienter som hadde gjennomgått tidlig postoperativ blødning.

\section{HOVEDFUNN}

Tonsilleoperasjon ble utført hos 1394 pasienter ved Ålesund sjukehus i perioden 2015-19.

Av disse fikk 2,2 \% tidlig blødning innen 24 timer etter operasjon, mens 1,4 \% fikk seinblødning.

o,4\% måtte reopereres grunnet seinblødning.

Pasienter over 15 år og pasienter med tidlig postoperativ blødning hadde økt risiko for seinblødning.

\section{LITTERATUR:}

1. Helseatlas. Senter for klinisk dokumentasjon og evaluering (SKDE). https://helseatlas.no/ Lest 28.1.2021.

2. Johnson LB, Elluru RG, Myer CM. Complications of adenotonsillectomy. Laryngoscope 2002; 112: 35-6. [PubMed][CrossRef] 
3. De Luca Canto G, Pachêco-Pereira C, Aydinoz S et al. Adenotonsillectomy complications: A metaanalysis. Pediatrics 2015; 136: 702-18. [PubMed][CrossRef]

4. Wall JJ, Tay KY. Postoperative tonsillectomy hemorrhage. Emerg Med Clin North Am 2018; 36: 415-26. [PubMed][CrossRef]

5. Østvoll E, Sunnergren O, Ericsson E et al. Mortality after tonsil surgery, a population study, covering eight years and 82,527 operations in Sweden. Eur Arch Otorhinolaryngol 2015; 272: 737-43.

[PubMed][CrossRef]

6. Lowe D, van der Meulen J, Cromwell D et al. Key messages from the National Prospective Tonsillectomy Audit. Laryngoscope 2007; 117: 717-24. [PubMed][CrossRef]

7. Windfuhr JP, Chen YS, Remmert S. Hemorrhage following tonsillectomy and adenoidectomy in 15,218 patients. Otolaryngol Head Neck Surg 2005; 132: 281-6. [PubMed][CrossRef]

8. Windfuhr JP, Chen YS. Do changing trends in tonsil surgery affect hemorrhage rates? A longitudinal study covering 1,452,637 procedures. Eur Arch Otorhinolaryngol 2019; 276: 2585-93.

[PubMed][CrossRef]

9. Tomkinson A, Harrison W, Owens D et al. Risk factors for postoperative hemorrhage following tonsillectomy. Laryngoscope 2011; 121: 279-88. [PubMed][CrossRef]

10. Lowe D, van der Meulen J. Tonsillectomy technique as a risk factor for postoperative haemorrhage. Lancet 2004; 364: 697-702. [PubMed][CrossRef]

11. Østvoll E, Sunnergren O, Stalfors J. Increasing readmission rates for hemorrhage after tonsil surgery: A longitudinal (26 Years) national study. Otolaryngol Head Neck Surg 2018; 158: 167-76. [PubMed][CrossRef]

12. Söderman AC, Odhagen E, Ericsson E et al. Post-tonsillectomy haemorrhage rates are related to technique for dissection and for haemostasis. An analysis of 15734 patients in the National Tonsil Surgery Register in Sweden. Clin Otolaryngol 2015; 40: 248-54. [PubMed][CrossRef]

13. Pinder DK, Wilson H, Hilton MP. Dissection versus diathermy for tonsillectomy. Cochrane Database Syst Rev 2011; 2011: CDoo2211. [PubMed]

14. Pynnonen M, Brinkmeier JV, Thorne MC et al. Coblation versus other surgical techniques for tonsillectomy. Cochrane Database Syst Rev 2017; 8: CDoo4619. [PubMed][CrossRef]

15. Liu JH, Anderson KE, Willging JP et al. Posttonsillectomy hemorrhage: what is it and what should be recorded? Arch Otolaryngol Head Neck Surg 2001; 127: 1271-5. [PubMed][CrossRef]

16. Wennberg S, Amundsen MF, Bugten V. Årsrapport 2019. Trondheim: Norsk tonsilleregister, 2020. https://www.kvalitetsregistre.no/sites/default/files/45xx_arsrapport_2019_tonsilleregisteret.pdf Lest 28.1.2021.

17. Mueller J, Boeger D, Buentzel J et al. Population-based analysis of tonsil surgery and postoperative hemorrhage. Eur Arch Otorhinolaryngol 2015; 272:3769-77. [PubMed][CrossRef]

18. Elinder K, Söderman AC, Stalfors J et al. Factors influencing morbidity after paediatric tonsillectomy: a study of 18,712 patients in the National Tonsil Surgery Register in Sweden. Eur Arch Otorhinolaryngol 2016; 273: 2249-56. [PubMed][CrossRef]

19. Omrani M, Barati B, Omidifar N et al. Coblation versus traditional tonsillectomy: A double blind randomized controlled trial. J Res Med Sci 2012; 17: 45-50. [PubMed]

20. Wei JL, Beatty CW, Gustafson RO. Evaluation of posttonsillectomy hemorrhage and risk factors. Otolaryngol Head Neck Surg 2000; 123: 229-35. [PubMed][CrossRef]

21. Ginström R, Silvola J, Saarnivaara L. Local bupivacaine-epinephrine infiltration combined with general anesthesia for adult tonsillectomy. Acta Otolaryngol 2005; 125: 972-5. [PubMed][CrossRef]

22. Bameshki AR, Razban M, Khadivi E et al. The effect of local injection of epinephrine and bupivacaine on post-tonsillectomy pain and bleeding. Iran J Otorhinolaryngol 2013; 25: 209-14. [PubMed]

23. Magdalena ML, Solé A, Blanco V et al. Histological analysis of tonsillectomies: relationship with surgical technique, post-operative pain and haemorrhage. J Laryngol Otol 2016; 130: 1142-6.

[PubMed][CrossRef] 
24. Kim MK, Lee JW, Kim MG et al. Analysis of prognostic factors for postoperative bleeding after tonsillectomy. Eur Arch Otorhinolaryngol 2012; 269: 977-81. [PubMed][CrossRef]

25. Ikoma R, Sakane S, Niwa K et al. Risk factors for post-tonsillectomy hemorrhage. Auris Nasus Larynx 2014; 41:376-9. [PubMed][CrossRef]

26. Hinton-Bayre AD, Noonan K, Ling $S$ et al. Experience is more important than technology in paediatric post-tonsillectomy bleeding. J Laryngol Otol 2017; 131: S35-40. [PubMed][CrossRef]

27. Zhang LY, Zhong L, David M et al. Tonsillectomy or tonsillotomy? A systematic review for paediatric sleep-disordered breathing. Int J Pediatr Otorhinolaryngol 2017; 103: 41-50. [PubMed][CrossRef]

28. Odhagen E, Stalfors J, Sunnergren O. Morbidity after pediatric tonsillotomy versus tonsillectomy: A population-based cohort study. Laryngoscope 2019; 129: 2619-26. [PubMed][CrossRef]

29. Odhagen E, Sunnergren O, Hemlin C et al. Risk of reoperation after tonsillotomy versus tonsillectomy: a population-based cohort study. Eur Arch Otorhinolaryngol 2016; 273:3263-8.

[PubMed][CrossRef]

Publisert: 22. mars 2021. Tidsskr Nor Legeforen. DOI: 10.4045/tidsskr.20.0813 Mottatt 9.10.2020, første revisjon innsendt 30.11.2020, godkjent 28.1.2021.

(C) Tidsskrift for Den norske legeforening 2020. Lastet ned fra tidsskriftet.no 